\title{
Peran Manajemen Sumberdaya Manusia di Masa Pandemi COVID-19
}

\author{
Oleh: Muh. Fajar Purwantoro
}

Departemen manajemen sumber daya manusia yang dijalankan secara efisien dapat memberi organisasi Anda struktur dan kemampuan untuk memenuhi kebutuhan bisnis melalui pengelolaan sumber daya paling berharga perusahaan Anda dan karyawannya. Ada beberapa disiplin SDM, tetapi praktisi SDM di setiap disiplin dapat melakukan lebih dari satu dari lebih dari beberapa fungsi penting. Dalam bisnis kecil tanpa departemen manajemen sumberdaya manusia yang khusus, dapat dimungkinkan untuk mencapai tingkat efisiensi dan manajemen tenaga kerja yang sama melalui outsourcing fungsi SDM atau bergabung dengan organisasi pemberi kerja profesional (Mayhew, 2019). Manajemen sumberdaya manusia adalah manajemen tanggung jawab untuk produktivitas dan hubungan konstruktif organisasi dengan karyawannya (Purnomo, Putri and Rosyidah, 2017).

Kasus pandemik COVID-19 perlu diselesaikan oleh semua pihak secara gotong royong agar tuntas (Safitri et al., 2020). Instropeksi diri dan evaluasi bangsa Indonesia perlu dilakukan mendalam agar memberikan solusi atas pandemic COVID-19 ini (Masrul et $a l ., 2020)$. Manajemen SDM pun perlu menyesuaikan diri terhadap masalah Coronavirus. Berikut adalah beberapa peran manajemen sumberdaya manusia di masa pandemik COVID-19.

\section{Kepegawaian}

Fungsi kepegawaian ini termasuk aktivitas mempekerjakan karyawan penuh waktu atau paruh waktu baru, menyewa kontraktor, dan mengakhiri kontrak karyawan. Aktivitas kepegawaian meliputi: mengidentifikasi dan memenuhi kebutuhan bakat (terutama melalui rekrutmen), memanfaatkan berbagai teknologi rekrutmen untuk mendapatkan pelamar dalam jumlah besar (dan untuk menyaring berdasarkan pengalaman), mengakhiri kontrak bila perlu, mempertahankan praktik perekrutan yang etis dan menyelaraskan dengan peraturan lingkungan, dan menulis kontrak karyawan dan menegosiasikan gaji dan tunjangan (Lumencandela, 2021).

\section{Ketangkasan dalam Organisasi SDM dengan Cepat Beraksi}

Di saat pandemic COVID-19 di mana penyelarasan untuk bekerja dan tenaga kerja dibutuhkan lebih dari sebelumnya. Penyelarasan fungsional tradisional adalah sesuatu yang anda perlu yakini harus dipertimbangkan kembali. Anda harus memulai dengan meningkatkan ketangkasan organisasi SDM Anda (Ubachs and Ulrici, 2020). 


\section{Pekerjaan Jarak Jauh Ada dari Rumah}

Banyak pekerjaan yang sebelumnya tidak jauh sekarang dan tidak akan berubah dalam waktu dekat pasca pandemic COVID-19. Perusahaan melihat manfaat memiliki karyawan yang bekerja dari rumah (work from home). Dan beberapa karyawan suka tidak ada perjalanan atau gangguan dari kantor. Manajer SDM perlu menyesuaikan peran mereka juga untuk mengakomodasi karyawan yang bekerja dari jarak jauh. Ini akan mencakup beberapa aspek, termasuk keterlibatan karyawan, akuisisi bakat, dan kepatuhan hukum, yang akan kita lihat di bawah (HireHive Team, 2020).

\section{Menjaga Lingkungan yang Aman}

Keamanan tempat kerja merupakan faktor penting. Berdasarkan Undang-undang Keselamatan dan Kesehatan Kerja, pemberi kerja berkewajiban untuk menyediakan lingkungan kerja yang aman bagi karyawan. Salah satu fungsi utama manajemen SDM adalah untuk mendukung pelatihan keselamatan tempat kerja dan memelihara log yang diamanatkan oleh pemerintah federal untuk pelaporan cedera dan kematian di tempat kerja. Selain itu, spesialis keselamatan dan risiko SDM sering bekerja sama dengan spesialis tunjangan SDM untuk mengelola masalah kompensasi pekerja perusahaan (Mayhew, 2019).

\section{Kompensasi}

Gaji dan tunjangan juga berada dalam ruang lingkup manajemen sumber daya manusia. Ini termasuk mengidentifikasi kompensasi yang sesuai berdasarkan peran, kinerja, dan persyaratan hukum (Lumencandela, 2021).

\section{Menjadi organisasi SDM yang Tangguh secara finansial}

Titik awal dari manajemen SDM saat pandemi COVID-19 adalah berfokus pada pengembangan organisasi SDM yang tangguh secara finansial. Meskipun organisasi sering beralih ke SDM untuk menghemat biaya melalui manajemen tenaga kerja, selama masa krisis pandemic COVID-19 ini ada juga potensi yang belum dimanfaatkan untuk menghemat biaya dalam fungsi SDM itu sendiri (Ubachs and Ulrici, 2020).

\section{Strategi Baru}

Dari kepercayaan hingga mencari bantuan saat Anda membutuhkannya, pemimpin SDM di masa pandemic COVID-19 ini menawarkan strategi bagi para pemimpin SDM di dunia yang terus berubah ini. Strategi yang solid dapat membantu organisasi mengatasi krisis yang sedang berlangsung. Kemitraan perusahaan dengan media sosial akan menghemat waktu dan uang gaji karyawan (HRE Editorial Staff, 2021).

\section{Kepatuhan Aturan Perusahaan dan Pemerintah di Tempat Kerja Jarak Jauh}

Mengelola tenaga kerja jarak jauh juga akan membutuhkan kepatuhan aturan perusahaan dan pemerintah yang berbeda. Hal spesifik terkait undang-undang ketenagakerjaan akan bergantung pada negara atau negara bagian Anda. SDM akan menjadi kunci untuk 
menjaga kepatuhan ini. Anda akan ingin melihat kebijakan saat ini seperti cuti dibayar, cuti sakit, dan cuti keluarga. Di mana Anda bisa melakukan perbaikan, terutama bagi pekerja yang sekarang ada di rumah?. Anda juga perlu memastikan bahwa kebijakan kerja jarak jauh Anda sesuai dengan persyaratan tenaga kerja setempat. Menggunakan sistem yang dapat membantu Anda melacak kepatuhan dan proses perekrutan akan menjadi langkah besar ke arah yang benar (HireHive Team, 2020).

\section{Manajemen kinerja}

Manajemen kinerja penting untuk memastikan bahwa pekerja tetap produktif dan terlibat di saat pandemic COVID-19. Manajemen kinerja yang baik melibatkan kepemimpinan yang baik, penetapan tujuan yang jelas, dan umpan balik terbuka. Alat manajemen kinerja mencakup tinjauan kinerja tahunan, di mana karyawan ditinjau oleh manajernya. Ini juga mencakup alat umpan balik aktif di mana rekan kerja, manajer, bawahan, dan terkadang bahkan pelanggan meninjau kinerja karyawan. Alat semacam ini bisa sangat membantu dalam memberikan umpan balik. Manajemen kinerja juga merupakan instrumen untuk menutup kesenjangan antara tenaga kerja yang Anda miliki saat ini dan yang ingin Anda miliki di masa depan. Salah satu cara terbaik untuk membangun tenaga kerja masa depan Anda adalah melalui pembelajaran dan pengembangan (Vulpen, 2020).

\section{Liburan dan Cuti Sakit}

Cuti berbayar yang mencakup liburan, cuti sakit dan hari pribadi, juga dapat ditangani oleh administrator manfaat. Namun, untuk tujuan pencatatan, beberapa perusahaan meminta pegawai penggajian mereka menangani masalah ini dengan pengecualian permintaan cuti. Kebijakan dan prosedur SDM terkait cuti harus diungkapkan dengan jelas dan disebarluaskan kepada karyawan, supervisor dan manajer, karena penyalahgunaan cuti dapat mengakibatkan tindakan disipliner atau pemutusan hubungan kerja (Mayhew, 2019).

\section{Rekrutmen dan seleksi}

Fungsi SDM juga melibatkan menarik orang untuk bekerja untuk organisasi dan memilih kandidat terbaik. Menarik orang baru biasanya dimulai dengan merekrut karyawan. Menjadi perusahaan yang menarik memiliki banyak keuntungan - seperti halnya sebaliknya (Vulpen, 2020).

\section{References}

HireHive Team (2020) The Role of Human Resources in a Post-COVID-19 World, HireHive. Available at: https://hirehive.com/role-human-resources-post-covid-19world/.

HRE Editorial Staff (2021) Collection: Strategies to manage coronavirus in the workplace, Human Resource Executive. Available at: https://hrexecutive.com/a-dailyshot-your-covid-19-update-2-2/. 
Lumencandela (2021) The Functions and Goals of HR, Lumencandela. Available at: https://courses.lumenlearning.com/boundless-business/chapter/the-functions-and-goalsof-hr/.

Masrul et al. (2020) Pandemik COVID-19: Persoalan dan Refleksi di Indonesia. Medan: Yayasan Kita Menulis.

Mayhew, R. (2019) Six Main Functions of a Human Resource Department, Hearst Newspapers, LLC. Available at: https://smallbusiness.chron.com/six-main-functionshuman-resource-department-60693.html.

Purnomo, A., Putri, R. A. and Rosyidah, E. (2017) Kamus Manajemen Sumber Daya Manusia. Sidoarjo: UNUSIDA Press.

Safitri, Y. et al. (2020) Gotong Royong Menghadapi COVID-19: Ide dan Solusi. Pasuruan: CV. Penerbit Qiara Media. Available at: https://books.google.co.id/books?id=AT8DEAAAQBAJ.

Ubachs, C. and Ulrici, E. (2020) The future of HR in the face of COVID-19, Deloitte Touche Tohmatsu Limited. Available at: https://www2.deloitte.com/nl/nl/pages/humancapital/articles/the-future-of-hr-in-the-face-of-covid-19.html.

Vulpen, E. van (2020) The 12 Key Functions of Human Resources, AIHR. Available at: https://www.digitalhrtech.com/human-resources-functions/. 